\title{
Trends in Health Professions: Disclosure of Records to Third Parties
}

\section{O gOWLING WLG bms.}

This article was prepared and written by the BMS Group Healthcare Professionals Insurance Alliance legal team of Gowling WLG (Canada) LLP (Gowlings), one of the largest and most highly-recognized legal firms in medical defence and professional liability in Canada. In the event of an actual or potential professional liability claim, CAO members who participate in the Professional Liability Insurance program are eligible for 30-minute pro bono and inclusive legal claims defence services from Gowlings.

Gowlings Pro Bono Legal Advice line: 1-844-792-2022

$\mathrm{T}$

he protection of a patient's personal health information is a key element of practising defensively. This article will provide some guidance regarding the steps that optometrists should take in response to a third-party request for the disclosure of confidential patient information to ensure that there is no breach of patient privacy.

Most optometry regulators have specific privacy-protection requirements for their respective licensees and members. In addition, federal and provincial privacy legislation sets standards that must be met, with the potential consequence of legal action should there be a breach.

Failure to properly protect a patient's confidential information can result in complaints to, and investigations by, your regulator as well as by the privacy commissioner. Further, it can expose you to civil liability under common law and privacy legislation. Failure to properly protect a patient's confidential information has the potential to interrupt your optometry practice and affect your professional reputation.

PRIVATE INFORMATION AND THE LAW

In Canada, personal health information is almost always considered sensitive personal information that is subject to privacy laws. ${ }^{1}$ The collection, use and disclosure of personal health information requires the informed consent of the patient and that the information only be collected, used and disclosed for the purposes consented to by the patient. The requirement for consent is ongoing and if a new use or disclosure becomes necessary, but has not been consented to, you must obtain consent from the patient for that new use or disclosure, unless there is an exception or it would be inappropriate to do so. ${ }^{2}$

Federal and provincial privacy legislation sets parameters for the proper collection, use and disclosure of personal health information by private organizations and individuals. The federal statute governing personal information is the Personal Information Protection and Electronic Documents Act ("PIPEDA"). ${ }^{3}$ Some provinces have privacy legislation and PIPEDA does not apply where provincial legislation is declared "substantially similar". ${ }^{4}$ In some provinces, legislation governing personal health information has not yet been declared substantially similar to PIPEDA. ${ }^{5}$ In addition to federal and provincial legislation, a common law right to privacy is now recognized by some Canadian courts. ${ }^{6}$ Therefore, ensuring compliance with privacy law may require consultation with legal counsel.

\section{DISCLOSURE TO THIRD PARTIES}

The need to disclose personal health information to third parties can arise in a wide variety of circumstances. A common example is where an optometrist determines the need to refer a patient to another regulated health professional (for instance, an ophthalmologist), for consultation or further treatment. In this instance, privacy laws deem that the consent to share information with the healthcare professional for a referral is covered by implied consent of the patient for the provision of health care, unless the patient has expressly withheld or withdrawn his or her consent.? 
However, it is not uncommon for requests for disclosure of patient information to third parties to arise outside of the strict provision of health care. In these circumstances, it is important for you to carefully consider whether informed consent to disclose the information has been obtained, or is required in the particular circumstances.

Questions for optometrists to consider when determining whether informed consent has been obtained to permit disclosure of personal health information to a third party include:

- Who gave the initial consent to gather the personal health information of the patient?

- Does that individual who originally provided consent still have authority to consent?

- Is the initial consent still ongoing and did the initial consent provide for disclosure to a third party in a circumstance such as this?

- What other substitute decision-makers have authority to provide consent?

Satisfying yourself that you have the requisite consent to disclose personal health information to a third party is not always a straightforward task. The Information and Privacy Commissioner of Ontario's guidelines provide a good example of how competing interests can make consent to disclosure a potential minefield for healthcare professionals. ${ }^{8}$ To assist, we have outlined some common examples below.

\section{Patient is a minor or has a disability}

When the patient is a minor or has a disability, the consent to disclose personal health information may require the written consent of a parent or legal guardian. ${ }^{9}$

Imagine that a fourteen-year-old patient comes to you for an optometric assessment, accompanied by her father who has rights of access under a child custody arrangement with the mother, who has custody of the teen. Prior to the optometric assessment, the teen was involved with learning support staff at her school, and the father wishes the optometrist to provide them private information about the assessment. Can the optometrist disclose private information at the request of the father alone?

The short answer in this circumstance is most often 'no'. Under privacy law, for minors, the right to consent on their behalf generally only rests with a substitute decision-maker. Parents with custody of the minor, not those with mere access rights, generally have the authority necessary to consent to disclosure on behalf of the minor. However, even minors who have themselves made the decision to consent to treatment can also provide consent to disclose personal health information to third parties, provided that this consent is informed and expressed. ${ }^{10}$

\section{You receive a court order, summons or subpoena}

If the request for disclosure to a third party is required by law (for example, pursuant to a court order), then the informed consent of the patient is not required under privacy law. Upon receipt of a court order, summons or subpoena, you should review the document carefully to determine when you are required to disclose the information (i.e. if you receive a summons or subpoena, you may only need to bring the pertinent documents with you when you are required to attend at Court on a specified date). You should also call the individual (most often a lawyer) who provided the court order, summons or subpoena to discuss the scope of the documentary request.

When such an order is received, a best practice would also be to inform the patient of the court order, summons, or subpoena prior to making the disclosure.

\section{Requests from a third party with a signed patient authorization}

Sometimes, health professionals will receive a third-party disclosure request from a patient's lawyer or representative. Typically, these requests will be accompanied by a signed consent form from the patient. When such a request is received, best practice is always to contact the patient directly to confirm the patient's consent and to discuss the information that will be disclosed pursuant to the request. This will ensure that the patient's consent is informed and the patient understands the content of the record prior to it being disclosed. Optometrists should keep detailed records of these conversations. 
Sometimes a third-party request will include a request for information or confirmation that a certain event, injury, or accident had an effect on the patient's health status. For example, consider a patient who sustained injuries in a motor vehicle accident resulting in legal action. An optometrist receives a request from the patient's lawyer to provide past exam information including any "proof" establishing that the patient's eyesight was affected by the accident.

First, it is important for health professionals to distinguish between a role as a treating health professional and a role as an expert. In these circumstances, the optometrist may ultimately provide records and factual information arising from treatment of the patient that will ultimately assist the patient in establishing their claim. However, the role of the treating professional does not include providing expert opinion. If such a request is received, optometrists should clarify their role with the patient and the lawyer.

\section{Fees for disclosure requests}

When a request is made for the disclosure of a patient's record, optometrists are typically entitled to request a reasonable fee for providing such records. Optometrists should consult their provincial association's fee guides, which usually set standard fees for record-related requests. As a general principle, any fees charged should be reasonable, and best practice is to ensure they are consistent with the suggested fees established by the local provincial association.

Finally, optometrists must always remember to inform, preferably in writing, the individual providing the informed consent and the third party receiving the information of the purpose for which the information is being disclosed and any conditions on its disclosure. You should always keep records of the informed consent, the disclosure itself, and the purposes and conditions of the disclosure to the third party. In addition, if the information that was disclosed changes or is discovered to be incorrect, you may be under an obligation to update the third party of such changes or corrections and a provision for that scenario should be expressly stated in the patient's consent to disclose to the third party.

Informed consent is a baseline requirement for the provision of health care, as well as for the use and disclosure of personal health information. Optometrists who are conscientious of their patient's privacy rights and their professional duty to protect privacy will obtain informed consent to disclose information to third parties, and will systematically document those disclosures in accordance with the standards of the professional regulator. $\bullet$

Please note that this commentary is not, nor should it be considered, legal advice and should not be relied upon as such. Should you have any questions regarding patient/client privacy rights as it relates to your practice, please contact your provincial association, your provincial regulator and/or consult legal counsel.

\section{REFERENCES}

1. Personal Information Protection and Electronic Documents Act, SC 2000, c 5, Sched 1, s 4.3.4 [PIPEDA].

2. The Model Code for the Protection of Personal Information under PIPEDA states that: "In certain circumstances personal information can be collected, used, or disclosed without the knowledge and consent of the individual. For example, legal, medical, or security reasons may make it impossible or impractical to seek consent. When information is being collected for the detection and prevention of fraud or for law enforcement, seeking the consent of the individual might defeat the purpose of collecting the information. Seeking consent may be impossible or inappropriate when the individual is a minor, seriously ill, or mentally incapacitated. In addition, organizations that do not have a direct relationship with the individual may not always be able to seek consent. For example, seeking consent may be impractical for a charity or a direct-marketing firm that wishes to acquire a mailing list from another organization. In such cases, the organization providing the list would be expected to obtain consent before disclosing personal information."

3. PIPEDA, Sched 1, supra note 1.

4. Provincial statutes that have been declared "substantially similar" to PIPEDA by the federal government include: Personal Information Protection Act, SBC 2003, c 63; Personal Information Protection Act, SA 2003, c P-6.5; Personal Health Information Protection Act, 2004 SO, c 3; An Act respecting the protection of personal information in the private sector, RSQ c P-39.1; Personal Health Information Privacy and Access Act, SNB 2009, c P-7.05; Personal Health Information Act, SNL 2008, c P-7.01.
5. Provincial health information statutes that have not been declared "substantially similar" to PIPEDA include: Personal Health Information Act, CCSM c P33.5; Personal Health Information Act, SNS 2010, c 41; The Health Information Protection Act, SS 1999, c H-0.021.

General privacy legislation that has not been declared "substantially similar" to PIPEDA includes: Access to Information and Protection of Privacy Act, RSY 2002, c 1; Freedom of Information and Protection of Privacy Act, RSPEI 1988, c F-15.01; Access to Information and Protection of Privacy Act, SNWT (Nu) 1994, c 20.

6. It appears that the courts will allow liability at common law for breach of privacy in the medical context to coexist with liability under provincial health information legislation: see Hopkins v Kay, 2014 ONSC 321 applying Jones v Tsige, 2012 ONCA 32.

7. See Information and Privacy Commissioner of Ontario, "A Guide to the Personal Health Information Protection Act” (December 2004) at 12, online: Information and Privacy Commissioner < https://www. ipc.on.ca/images/resources/hguide-e.pdf $>$ [Guide to PHIPA].

8. Guide to PHIPA, ibid at 14 .

9. Guide to PHIPA, ibid at 13 .

10. Guide to PHIPA, ibid at 13,14 .

11. PIPEDA, Sched 1, supra note 1, s 4.9.5. 